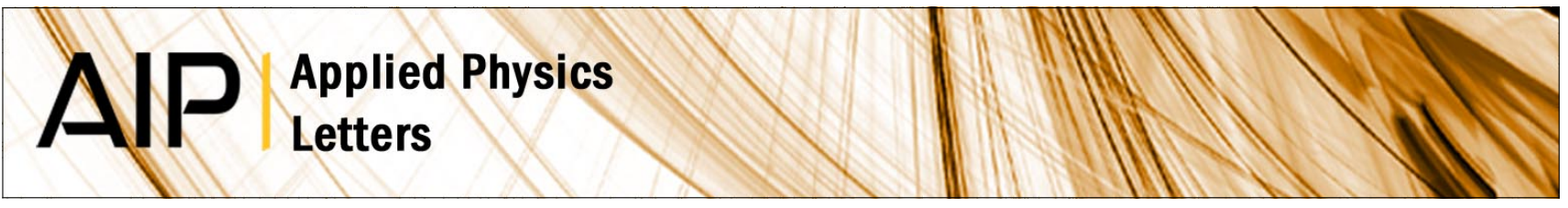

\title{
Self-diffusion in germanium isotope multilayers at low temperatures
}

E. Hüger, U. Tietze, D. Lott, H. Bracht, D. Bougeard et al.

Citation: Appl. Phys. Lett. 93, 162104 (2008); doi: 10.1063/1.3002294

View online: http://dx.doi.org/10.1063/1.3002294

View Table of Contents: http://apl.aip.org/resource/1/APPLAB/v93/i16

Published by the American Institute of Physics.

\section{Related Articles}

In situ observation of nickel as an oxidizable electrode material for the solid-electrolyte-based resistive random access memory

Appl. Phys. Lett. 102, 053502 (2013)

Probing the hydrogen equilibrium and kinetics in zeolite imidazolate frameworks via molecular dynamics and quasi-elastic neutron scattering experiments

J. Chem. Phys. 138, 034706 (2013)

Experimental evidence of superionic conduction in $\mathrm{H} 2 \mathrm{O}$ ice

J. Chem. Phys. 137, 194505 (2012)

The role of Anderson-Gruneisen parameter in the estimation of self-diffusion coefficients in alkaline earth oxides J. Appl. Phys. 112, 096101 (2012)

Proton conduction related electrical dipole and space charge polarization in hydroxyapatite J. Appl. Phys. 112, 074901 (2012)

\section{Additional information on Appl. Phys. Lett.}

Journal Homepage: http://apl.aip.org/

Journal Information: http://apl.aip.org/about/about_the_journal

Top downloads: http://apl.aip.org/features/most_downloaded

Information for Authors: http://apl.aip.org/authors

\section{ADVERTISEMENT}

\section{AIP Applied Physics Letters}

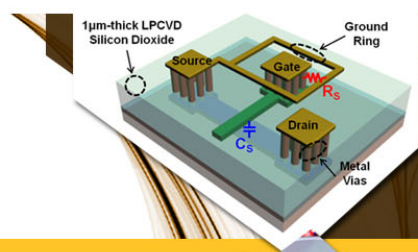

\section{SURFACES AND} INTERFACES

Focusing on physical, chemical, biological structural, optical, magnetic and electrical properties of surfaces and interfaces, and more..

\section{EXPLORE WHAT'S NEW IN APL}

SUBMIT YOUR PAPER NOW!
ENERCY CONVERSION AND STORACE 


\title{
Self-diffusion in germanium isotope multilayers at low temperatures
}

\author{
E. Hüger, ${ }^{1, a)}$ U. Tietze $^{2}$ D. Lott, ${ }^{2}$ H. Bracht, ${ }^{3}$ D. Bougeard, ${ }^{4}$ E. E. Haller, ${ }^{5}$ and \\ H. Schmidt ${ }^{1}$ \\ ${ }^{1}$ Institut für Metallurgie, Technische Universität Clausthal, AG Materialphysik, \\ Robert-Koch-Strasse 42, D-38678 Clausthal-Zellerfeld, Germany \\ ${ }^{2}$ GKSS Forschungszentrum Geesthacht GmbH, Max-Planck-Strasse 1, D-21502 Geesthacht, Germany \\ ${ }^{3}$ Institut für Materialphysik, Universität Münster, Wilhelm-Klemm-Strasse 10, D-48149 Münster, Germany \\ ${ }^{4}$ Walter Schottky Institut, Technische Universität München, Am Coulombwall 3, D-85748 Garching, \\ Germany \\ ${ }^{5}$ University of California at Berkeley and Lawrence Berkeley National Laboratory, 1 Cyclotron Road, \\ Berkeley, California 94720, USA
}

(Received 9 September 2008; accepted 26 September 2008; published online 22 October 2008)

Self-diffusion in intrinsic single crystalline germanium was investigated between 429 and $596{ }^{\circ} \mathrm{C}$ using ${ }^{70} \mathrm{Ge} /{ }^{\text {nat }} \mathrm{Ge}$ isotope multilayer structures. The diffusivities were determined by neutron reflectometry from the decay of the first and third order Bragg peak. At high temperatures the diffusivities are in excellent agreement with literature data obtained by ion beam sputtering techniques, while considerably smaller diffusion lengths between 0.6 and $4.1 \mathrm{~nm}$ were measured. At lower temperatures the accessible range of diffusivities could be expanded to $D \approx 1$ $\times 10^{-25} \mathrm{~m}^{2} \mathrm{~s}^{-1}$, which is three orders of magnitude lower than the values measured by sputtering techniques. Taking into account available data on Ge self-diffusion, the temperature dependence is accurately described over nine orders of magnitude by a single Arrhenius equation. A diffusion activation enthalpy of $3.13 \pm 0.03 \mathrm{eV}$ and a pre-exponential factor of $2.54 \times 10^{-3} \mathrm{~m}^{2} \mathrm{~s}^{-1}$ for temperatures between 429 and $904{ }^{\circ} \mathrm{C}$ are obtained. Single vacancies are considered to prevail self-diffusion in Ge over the whole temperature range. (C) 2008 American Institute of Physics.

[DOI: $10.1063 / 1.3002294]$

Diffusion is a fundamental process of matter transport in solids, important for preparation, processing, and heat treatment of materials. ${ }^{1}$ The field of modern semiconductor science and technology and the generation of ultrashallow junctions during fabrication of electronic devices are typical examples. $^{2-5}$ The motion of native point defects (vacancies and self-interstitials) as well as defect reactions controls the kinetic behavior of dopants. ${ }^{6}$ A fundamental quantity is the self-diffusivity of the host atom in crystalline materials. From self-diffusion experiments with isotopically enriched heterostructures, important information on the properties of native point defects in $\mathrm{Si}^{7}{ }^{7} \mathrm{SiGe},{ }^{8} \mathrm{GaP},{ }^{9} \mathrm{GaAs},{ }^{10} \mathrm{GaSb},{ }^{11}$ $\mathrm{SiC},{ }^{12} \mathrm{SiN},{ }^{13}$ and $\mathrm{TiB}_{2}$ (Ref. 14) were obtained. The isotope heterostructures are chemically homogeneous solids, which are composed of a stack of isotope enriched layers (e.g., ${ }^{28} \mathrm{Si} /{ }^{30} \mathrm{Si}$ ) grown by suitable deposition techniques. The interdiffusion of stable isotopes during diffusion annealing takes place at the isotope interface(s) inside the crystal, unaffected by possible surface effects. Beside self-diffusion experiments, isotopically controlled heterostructures enable even more advanced diffusion studies such as investigations of radiation enhanced self-diffusion ${ }^{15,16}$ and the impact of dopant diffusion on self-diffusion. ${ }^{17,18}$ Such kinds of diffusion studies are difficult to realize with radiotracer techniques since radioactive elements possess limited half-lifes and are usually deposited on the sample surface or implanted with a low dose to minimize radiation damage.

Irrespective of the use of stable or radioactive isotopes commonly ion beam sputtering techniques ${ }^{1}$ are applied for measuring diffusion profiles after annealing. This technique

${ }^{\text {a)} E l e c t r o n i c ~ m a i l: ~ e r w i n . h u e g e r @ t u-c l a u s t h a l . d e . ~}$ is applicable to mean penetration depths of a few tens of nanometer, corresponding to diffusivities of about $10^{-22} \mathrm{~m}^{2} \mathrm{~s}^{-1}$ (see, e.g., Ref. 19). This limitation is caused by instrumental broadening of the profiles associated with the ion beam sputtering process. To detect even lower diffusion coefficients or to extend diffusion experiments to lower temperatures other instrumental methods need to be applied. In this respect, it has recently been demonstrated that isotopically enriched superlattice structures in conjunction with Raman scattering are suitable to detect the thermal broadening of ${ }^{70} \mathrm{Ge} /{ }^{74} \mathrm{Ge}$ (Ref. 20) and ${ }^{28} \mathrm{Si} /{ }^{30} \mathrm{Si}$ (Ref. 21) superlattices. Diffusion coefficients of the order of $10^{-25} \mathrm{~m}^{2} \mathrm{~s}^{-1}$ could be measured. Another approach has recently been demonstrated by Schmidt et al. ${ }^{22,23}$ By means of neutron reflectometry (NR) diffusion lengths down to $0.6 \mathrm{~nm}$ could be measured in $\mathrm{Si}^{14} \mathrm{~N}_{x} / \mathrm{Si}^{15} \mathrm{~N}_{x}$ isotope multilayers resulting in self-diffusion coefficients as low as $10^{-25} \mathrm{~m}^{2} \mathrm{~s}^{-1}$.

In order to test the capability of the method, NR is applied to measure self-diffusion in single crystalline $\mathrm{Ge}$. $\mathrm{Ge}$ is an important semiconductor with a high potential for future commercial fabrication of field effect transistors. ${ }^{3,5}$ At the same time information about fundamental properties of native point defects in Ge are required since all technological important dopant atoms utilize native point defects as diffusion vehicle. Self-diffusion in Ge is considered to be mainly mediated by vacancies, ${ }^{24-27}$ i.e., the contribution of selfinterstitials is assumed to be negligible. This result stems from the temperature and pressure dependence of selfdiffusion in Ge. The former experiments of Werner et al. ${ }^{24}$ were performed at temperatures between 535 and $904{ }^{\circ} \mathrm{C}$. In this temperature range Ge self-diffusion is accurately described with a single diffusion activation enthalpy of $3.09 \mathrm{eV}$. 


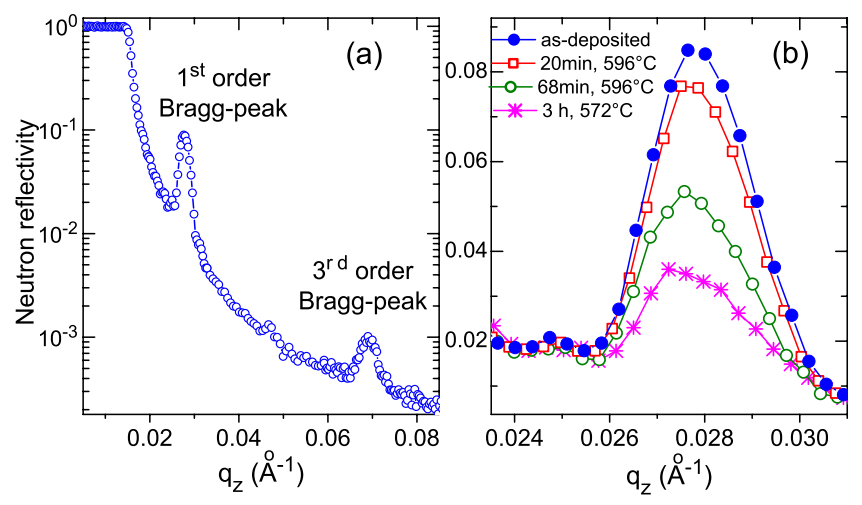

FIG. 1. (Color online) (a) NR of an as-deposited Ge isotope multilayer. (b) Decrease in first order Bragg peak after annealing the Ge isotope multilayer.

With the NR measurements we have extended the selfdiffusion experiments to temperatures as low as $429{ }^{\circ} \mathrm{C}$ to investigate whether or not the activation enthalpy of selfdiffusion changes at these low temperatures. A change in enthalpy would indicate an additional process governing self-diffusion.

The NR experiments were performed at the Geesthacht Neutron Facility at the polarized neutron reflectometer (PNR) using cold neutrons at incoming wavelength of 0.64 $\mathrm{nm}$. The measurements were carried out on single crystalline isotope multilayers containing 10 bilayers of the form $\left[{ }^{\text {nat }} \mathrm{Ge} /{ }^{70} \mathrm{Ge}\right]$, which were deposited on a (001) oriented ${ }^{\text {nat }} \mathrm{Ge}$ substrate by molecular beam epitaxy at $250{ }^{\circ} \mathrm{C}$. The samples were annealed inside a vacuum chamber at a pressure below $10^{-7}$ mbar at temperatures between 596 and $429{ }^{\circ} \mathrm{C}$ for times between $20 \mathrm{~min}$ and 39 days.

The NR measurements revealed a thickness of $14.1 \mathrm{~nm}$ for both the ${ }^{\text {nat }} \mathrm{Ge}$ and ${ }^{70} \mathrm{Ge}$ layers. For Ge, there exists a difference in the bound neutron scattering lengths of ${ }^{70} \mathrm{Ge}$ $(10.0 \mathrm{fm})$ and ${ }^{\text {nat }} \mathrm{Ge}(8.19 \mathrm{fm})$. Bragg peaks due to isotopic periodicity are measured in the neutron reflectivity pattern, as presented in Fig. 1. Peaks of first and third order can clearly be distinguished. When the isotope multilayer is isothermally annealed, the Bragg peak intensity decays with increasing annealing time [Fig. 1(b)]. The diffusivity can be calculated using

$$
D(T)=\frac{l^{2}}{8 \pi^{2} n^{2} t} \ln \left(\frac{I_{o}}{I(t)}\right),
$$

where $I_{o}$ is the intensity of the $n$th order Bragg peak at time $t=0, D$ is the diffusivity, $l$ is the bilayer periodicity, and $t$ is the annealing time. ${ }^{23}$

Figure 2 presents the self-diffusivities between 429 and $596{ }^{\circ} \mathrm{C}$ as obtained by NR. At temperatures between 525 and $600{ }^{\circ} \mathrm{C}$ our data are in excellent agreement with literature data measured by ion beam sputtering techniques. ${ }^{24,28}$ The data point for $500{ }^{\circ} \mathrm{C}$ measured by Raman scattering ${ }^{20}$ is also in agreement with our experimental results. Our diffusion study expands the range of experimental data by three orders of magnitude compared to results obtained with the sputtering techniques. At $429{ }^{\circ} \mathrm{C}$ a self-diffusion coefficient of as low as $D=(9.7 \pm 3.7) \times 10^{-26} \mathrm{~m}^{2} \mathrm{~s}^{-1}$ was measured. At $596{ }^{\circ} \mathrm{C}$ diffusion anneals for $20 \mathrm{~min}$ $\left[D=(1.50 \pm 0.32) \times 10^{-21} \mathrm{~m}^{2} \mathrm{~s}^{-1}\right]$ and $68 \mathrm{~min}[D$ $\left.=(1.63 \pm 0.35) \times 10^{-21} \mathrm{~m}^{2} \mathrm{~s}^{-1}\right]$ were performed. The corresponding diffusion values agree within experimental accu-

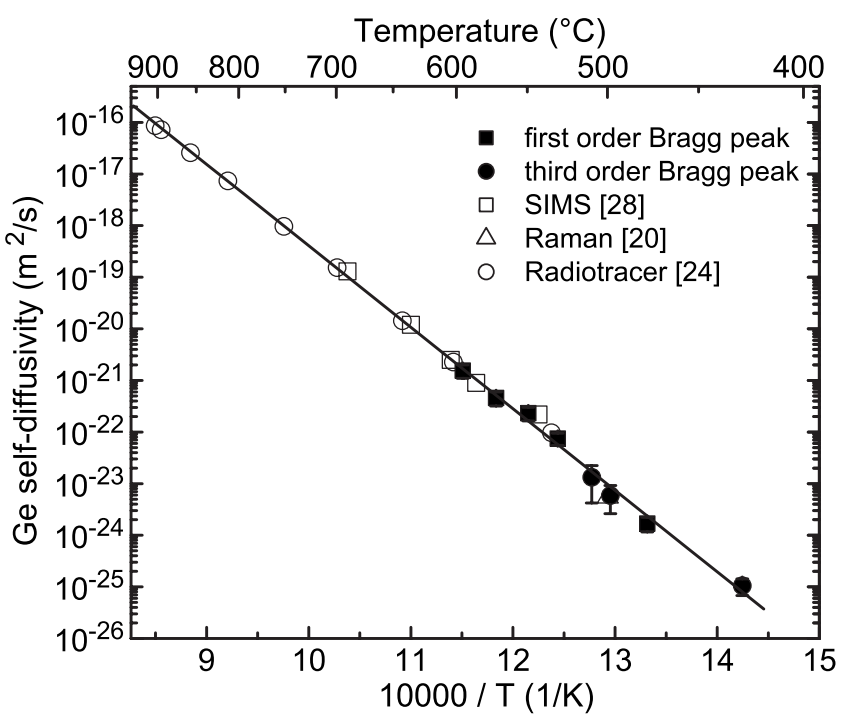

FIG. 2. Arrhenius plots of Ge self-diffusivities obtained by NR (filled circles and filled squares) in comparison to literature data from secondaryion-mass spectroscopy (SIMS), ${ }^{28}$ Raman spectroscopy, ${ }^{20}$ and radiotracer sputter sectioning. ${ }^{24}$ The continuous line represents a fit to the Arrhenius equation of all diffusivities displayed.

racy (see Fig. 2) indicating that the diffusion is not time dependent. A possible time dependence might be expected as a result of frozen in defects. Depending on the nature of these defects, i.e., vacancy or interstitial-like, they could give rise to transient enhanced or retarded self-diffusion.

An important quantity is the diffusion length $d$. In one dimension it is defined as $d=\sqrt{2 D t}$. The diffusion lengths determined by NR are in the range between 0.6 and $4.1 \mathrm{~nm}$ and significantly smaller than the diffusion lengths measured with conventional ion beam sputtering techniques. This also means that diffusion lengths of the order of $1 \mathrm{~nm}$ correctly characterize long range diffusion processes. According to Eq. (1) the diffusivity and diffusion length scale as $D_{n}=D_{1} / n^{2}$ and $d_{n}=d_{1} / n$, respectively. $D_{1}\left(d_{1}\right)$ and $D_{n}\left(d_{n}\right)$ are the diffusivity (diffusion length) of the first order and $n$th order Bragg peak. From this relationship it becomes evident that Bragg peaks of higher order have to be measured to detect diffusion lengths of the order of atomic jump distances. Such measurements are in progress.

As shown in Fig. 2 the diffusivities obtained by NR can be very well described by an Arrhenius equation $D$ $=D_{0} \exp [-Q /(k T)]$ with a single diffusion activation enthalpy $Q=3.13 \pm 0.12 \mathrm{eV}$ and a pre-exponential factor $D_{0}$ $=2.35 \times 10^{-3} \mathrm{~m}^{2} \mathrm{~s}^{-1}$ (relative error of $\ln \left(D_{0}\right): 29 \%$ ). Taking into account all data between 429 and $904{ }^{\circ} \mathrm{C}$, the Arrhenius parameters $Q=3.13 \pm 0.03 \mathrm{eV}$ and $D_{0}=2.54 \times 10^{-3} \mathrm{~m}^{2} \mathrm{~s}^{-1}$ are obtained. The parameters only slightly differ from $Q$ $=3.09 \mathrm{eV}$ and $D_{0}=1.3 \times 10^{-3} \mathrm{~m}^{2} \mathrm{~s}^{-1}$ reported by Werner et al. ${ }^{24}$ The strict Arrhenius behavior demonstrates that the vacancy mechanism, where the diffusing atom and a vacancy exchange sites during atomic motion, controls self-diffusion over the whole temperature range.

Summarizing, we have measured self-diffusion in single crystalline germanium isotope multilayers at temperatures between 429 and $596^{\circ} \mathrm{C}$ using neutron reflectometry. By means of this method the experimental data of Ge selfdiffusion could be expanded over three orders of magnitude to diffusivities down to $D \approx 1 \times 10^{-25} \mathrm{~m}^{2} \mathrm{~s}^{-1}$. Such low dif- 
fusion coefficients result in diffusion lengths below $1 \mathrm{~nm}$ for practical diffusion times that are hardly accessible by ion beam sputtering techniques. The Ge self-diffusion data given in the literature and in this work are accurately described with a single activation enthalpy $Q=3.13 \mathrm{eV}$ and a preexponential factor $D_{0}=2.54 \times 10^{-3} \mathrm{~m}^{2} \mathrm{~s}^{-1}$ for temperatures between 429 and $904{ }^{\circ} \mathrm{C}$. Single vacancies control selfdiffusion in Ge over the whole temperature range.

This research was supported by the German Research Foundation under Contract No. SCHM 1569/7-1. One of us (D.B.) acknowledges support by SFB 631 TPC4.

${ }^{1}$ H. Mehrer, Diffusion in Solids, Springer Series in Solid-State Sciences Vol. 155 (Springer, Berlin, 2007).

${ }^{2}$ H. J. Queisser and E. E. Haller, Science 281, 945 (1998).

${ }^{3}$ J. Vanhellemont and E. Simoen, J. Electrochem. Soc. 154, H572 (2007).

${ }^{4}$ H. A. Bracht, H. H. Silvestri, and E. E. Haller, Solid State Commun. 133, 727 (2005)

${ }^{5}$ H. A. Bracht, Diffus. Fundam. 8, 1.1 (2008).

${ }^{6}$ H. Bracht, Phys. Rev. B 75, 035210 (2007).

${ }^{7}$ H. Bracht, E. E. Haller, and R. Clark-Phelps, Phys. Rev. Lett. 81, 393 (1998).

${ }^{8}$ R. Kube, H. Bracht, J. Lundsgaard Hansen, A. Nylandsted Larsen, E. E. Haller, S. Paul, and W. Lerch, "Simultaneous diffusion of Si and Ge in isotopically controlled $\mathrm{Si}_{1-x} \mathrm{Ge}_{x}$ heterostructures," Mater. Sci. Semicond. Process. (to be published).

${ }^{9}$ L. Wang, J. A. Wolk, L. Hsu, E. E. Haller, J. W. Erickson, M. Cardona, T. Ruf, J. P. Silveira, and F. Briones, Appl. Phys. Lett. 70, 1831 (1997).

${ }^{10}$ H. Bracht, M. Norseng, E. E. Haller, K. Eberl, and M. Cardona, Solid State Commun. 112, 301 (1999).
${ }^{11}$ H. Bracht, S. P. Nicols, W. Walukiewicz, J. P. Silveira, F. Briones, and E. E. Haller, Nature (London) 408, 69 (2000).

${ }^{12}$ K. Rüschenschmidt, H. Bracht, N. A. Stolwijk, M. Laube, G. Pensl, and G. R. Brandes, J. Appl. Phys. 96, 1458 (2004).

${ }^{13}$ H. Schmidt, U. Geckle, and M. Bruns, Phys. Rev. B 74, 045203 (2006).

${ }^{14}$ H. Schmidt, G. Borchardt, C. Schmalzried, R. Telle, S. Weber, and H. Scherrer, J. Appl. Phys. 93, 907 (2003).

${ }^{15}$ H. Bracht, J. Fage Pedersen, N. Zangenberg, A. Nylandsted Larsen, E. E. Haller, G. Lulli, and M. Posselt, Phys. Rev. Lett. 91, 245502 (2003).

${ }^{16} \mathrm{~S}$. Schneider, H. Bracht, M. C. Pedersen, J. L. Hansen, and A. N. Larsen, J. Appl. Phys. 103, 033517 (2008).

${ }^{17}$ H. Bracht, H. H. Silvestri, I. D. Sharp, and E. E. Haller, Phys. Rev. B 75, 035211 (2007).

${ }^{18}$ S. Brotzmann, H. Bracht, J. Lundsgaard Hansen, A. Nylandsted Larsen, E. Simoen, E. E. Haller, J. S. Christensen, and P. Werner, Phys. Rev. B 77, 235207 (2008).

${ }^{19}$ P. Heitjans and S. J. Indris, J. Phys.: Condens. Matter 15, R1257 (2003).

${ }^{20}$ E. Silveira, W. Dondl, G. Abstreiter, and E. E. Haller, Phys. Rev. B 56 2062 (1997)

${ }^{21}$ Y. Shimizu, M. Uematsu, and K. M. Itoh, Phys. Rev. Lett. 98, 095901 (2007).

${ }^{22}$ H. Schmidt, M. Gupta, and M. Bruns, Phys. Rev. Lett. 96, 055901 (2006)

${ }^{23}$ H. Schmidt, M. Gupta, T. Gutberlet, J. Stahn, and M. Bruns, Acta Mater. 56, 464 (2008).

${ }^{24}$ M. Werner, H. Mehrer, and H. D. Hochheimer, Phys. Rev. B 32, 3930 (1985).

${ }^{25}$ A. Seeger and K. P. Chik, Phys. Status Solidi 29, 455 (1968).

${ }^{26}$ F. Frank, Defect Diffus. Forum 75, 121 (1991).

${ }^{27}$ A. Strohm, T. Voss, W. Frank, P. Laitinen, and J. Räisänen, Z. Metallkd. 93, 737 (2002).

${ }^{28}$ H. D. Fuchs, W. Walukiewicz, E. E. Haller, W. Dondl, R. Schorer, G. Abstreiter, A. I. Rudnev, A. V. Tikhomirov, and V. I. Ozhogin, Phys. Rev. B 51, 16817 (1995). 